\title{
https://doi.org/10.46813/2020-130-103 \\ REDISTRIBUTION OF SPUTTERED MATERIAL IN A PLANE ION- PLASMA SYSTEM WITH AN ABNORMAL GLOW DISCHARGE
}

\author{
A.I. Kuzmichev ${ }^{1}$, M.S. Melnichenko ${ }^{2}$, V.G. Shinkarenko ${ }^{1}$, V.M. Shulaev ${ }^{2}$ \\ ${ }^{1}$ Igor Sikorsky Kiev Polytechnic Institute, Kiev, Ukraine; \\ ${ }^{2}$ RPE “OTTOM", Ltd., Kharkiv, Ukraine \\ E-mail:ottom@ottom.com.ua; \\ E-mail:kuzmichev-kpi@ukr.net
}

The redistribution of the flow of sputtered material of a target (cathode) between the collector and the target in a plane-parallel electrode system with an anomalous glow discharge is analyzed in the kinetic approximation. Sputtering is the result of bombardment of the target by gas ions accelerated in the near-cathode space charge layer and by fast neutral atoms formed as a result of resonant ion charge exchange. Sputtered atoms partially return to the target due to collisions with gas molecules. The formulas were obtained, which were confirmed in the experiment that makes it possible to correctly estimate the ratio of the sputtered material flows deposited on the collector and the target. The results of the work are used to calculate the parameters of the processes of coating deposition and ion cleaning of the target under conditions of the anomalous glow discharge.

PACS: 81.15.Cd; 81.65.Cf

\section{INTRODUCTION}

Many types of treatment of materials and products in a gas discharge plasma use physical ion sputtering of the processed (treatment) object [1,2]. Ion sputtering, in particular, is used to clean and etch the surface of parts (called below as targets) before coating and nitriding, cementation, nitrocarburizing. In the electronic industry, ion sputtering is used to create microstructures on the substrate surface. The result of ion sputtering is the ejection of surface atoms from the target into the surrounding space due to its kinetic energy obtained as a result of energy exchange during the interaction of bombarding ions with target atoms [1-3].

In many ion-plasma systems, an abnormal glow discharge (AGD), the cathode of which is the target, is usually used to generate an ion flux to the target $[1,2,4]$. AGD voltage is hundreds of volts - several kilovolts, the current density is of the order of several milliamps per square centimeter. The pressure of the working gas (and as usual it is argon) is about $1 \ldots 50 \mathrm{~Pa}$.

Sputtered atoms are "waste" of the procedure of ion cleaning or etching, and it is obvious that they should be disposed of in some way so that they do not interfere with further processing of the target.

When these atoms move through a gaseous medium, they collide with gas molecules, give up the latters a part of their energy and change the direction of further movement. As a result, some of the sputtered atoms reach the wall of the process chamber opposite the target or the surface of another bodies, if any. Such bodies can be a substrate in the coating process or a special collector (trap) of sputtered species. The other part of the sputtered atoms returns back to the target, but to places remote from the emission place, and the third part goes to the side surfaces of the camera. If the target is larger than the distance to the collector (this situation is typical for plane ion-plasma systems), the interception of sputtered atoms by the lateral surface of the chamber plays a small role, and the collector must perform the main task of collecting sputtered species. Since the part of the sputtered atoms returns to the target, it is necessary to evaluate the redistribution of the sputtered material between the target and the collector.

Obviously, the smaller the gap $g$ between the target and the collector, the larger the fraction of sputtered atoms will be intercepted by the collector. However, the quantity $g$ must exceed the length $d$ of the dark cathode space, i.e. a layer of positive space charge (PSC), in which plasma ions acquire energy from an electric field [4]. This energy is necessary for ion sputtering of the target at a given rate and knocking out secondary cathode electrons. The cathode electrons accelerated in the PSC layer ionize the gas in the so-called negative glow (NG); this glow is a source of ions reaching the cathode [4]. It is generally accepted that in diode sputtering systems with AGD (target is a cathode, collector is an anode), the minimum distance $g$ should be larger than $1.5 d$. In this case, there are no problems with forming the NG plasma and generating ions for bombardment of the cathode. In AGD, almost all the discharge voltage $U$ drops on the PSC layer [4].

Formulas have been proposed for estimating the fraction of sputtered atoms reaching the collector in ion sputtering systems [2, 5]. In early works [5], it was assumed that the energy of sputtered atoms was equal to the thermal energy of gas particles, although the energy of the former is tens to hundreds of times greater than the energy of the latter, and therefore the calculated collection of sputtered atoms by the collector was greatly underestimated. In [2, p. 48-51], the indicated energy ratio was taken into account, but other simplifications were made for calculating mass transfer, due to which the calculated collection of sputtered atoms by the collector decreased at a much lower pressure than was observed in practice.

The aim of this work is to analyze the process of sputtering and mass transfer of sputtered atoms through a gaseous medium from the target surface to the collector surface under AGD conditions with planeparallel electrodes and to construct a method in the kinetic approximation for calculating the ratio of the parts of sputtered atoms collected by the collector and returning to the target. The calculation results will be 
compared with experimental data on the tantalum sputtering in argon medium [6]. This task is especially relevant for ion cleaning technologies, in which increased pressures of working gases are used in comparison with the high vacuum technology and multiple collisions of sputtered atoms with gas molecules occur.

\section{CALCULATION OF THE SPUTTERED ATOMS MOTION THROUGH A GASEOUS MEDIUM}

Consider the passage of sputtered metal atoms with an energy of several electron-volts through the braking medium of the working gas. We will deal with a planeparallel "target-collector" system. Due to the low thermal energy of gas molecules, they can be considered as immobile. A friction force $F$ acts on metal atoms:

$$
F=\left\langle m \frac{d v}{d t}\right\rangle,
$$

where $m$ is the sputtered atom mass, $v$ is the average atomic velocity; angle brackets indicate the average value. The average time interval between the collisions of metal atoms with gas molecules is

$$
d t=\left(\sigma_{a} n v\right)^{-1}
$$

where $\sigma_{a}$ is the cross section of metal atom-gas molecule interactions, and $n$ is the concentration of gas molecules. Assuming the interaction is elastic, we have the velocity after collision [7]:

$$
v=v_{0} \frac{m}{m+M}\left(\cos \Theta \mp \sqrt{(M / m)^{2}-\sin ^{2} \Theta}\right),
$$

where $v_{0}$ is the velocity of the metal atom before collision, $M$ is the gas molecules mass (later it is the mass of gas ions), $\Theta$ is the scattering angle. In this case, the directional velocity changes

$$
\begin{aligned}
& -d v=v_{0}-v \cos \Theta= \\
& =v_{0}\left[1-\frac{m \cos \Theta}{m+M}\left(\cos \Theta \pm \sqrt{(M / m)^{2}-\sin ^{2} \Theta}\right)\right] .
\end{aligned}
$$
form

The distribution function over the angles [7] has the

$$
\begin{aligned}
& f(\Theta)=\frac{1+(m / M)^{2} \cos 2 \Theta}{\sqrt{1-(m / M)^{2} \sin ^{2} \Theta}} \sin \Theta, \\
& 0 \leq \Theta \leq \arcsin (M / m) .
\end{aligned}
$$

Note, the distribution function over the angles for scattered particles is uniform or isotropic $[7,8]$.

Substituting (1) and (2) into the expression for $F$ and averaging over the angles, we obtain

$$
F=-\sigma_{a} n(m+M)^{-1} m M v^{2} .
$$

We use this expression to determine the dependence of the mass flux density of the sputtered material, $S_{m}(x)$, on distance $x$ from the target $(x=0)$ toward to the collector $(x=g)$

$$
S_{m}(x)=S_{m}(0) \exp \left(-x / \lambda_{a}\right),
$$

where the mean free path of the sputtered metal atoms is

$$
\lambda_{a}=(m+M) /\left(M \sigma_{a} n\right) .
$$

Note, the mass flux density $S_{m}(x)$ is related to the forward flying part of the total flux of sputtered atoms to the collector; the second part is the diffusionly scattered one [2, 8]. Accordingly, we can write the following expression for the total flux of sputtered atoms toward to the collector

$$
S_{m . t o t}(x)=S_{m}(0) \exp \left(-x / \lambda_{a}\right)-m D_{a}\left(d n_{a} / d x\right),
$$

where $D_{a}$ is the diffusion coefficient of metal atoms in the working gas, $n_{a}$ is the concentration of sputtered metal atoms. Integrating the last expression with the boundary conditions $n_{a}(x=0)=n_{a}(0)$ and $n_{a}(x=g)$, we obtain

$$
\begin{aligned}
& S_{m . t o t}(g)=m D_{a} n_{a}(0) / g+S_{m}(0)\left(\lambda_{a} / g\right) \times \\
& \times\left[1-\exp \left(-g / \lambda_{a}\right)\right] .
\end{aligned}
$$

Obviously, for metals under typical AGP conditions, the first term in the right side of (3) can be neglected compared to the second, and the maximum contribution from the exponent is about $15 \%$. From here we obtain the following formula

$$
S_{m}(g)=S_{m}(0) \lambda_{a} / g,
$$

where $S_{m}(g)$ is the mass flux density of sputtered material onto the collector. The back sputtered material deposition rate by mass onto the unit area of the target (or returning sputtered material onto the target) is

$$
B_{m}=S_{m}(0)\left(1-\lambda_{a} / g\right),
$$

as we consider

$$
S_{m}(g)+B_{m}=S_{m}(0) .
$$

Taking the density of the deposit condensate on the collector equal to the density of the target material, we obtain an expressions for determining the volumetric rates of deposition of the condensate on the collector, $D$, and of the back condensate on the target, $B$, respectively:

$$
\begin{gathered}
D=S \lambda_{a} / g, \\
B=S\left(1-\lambda_{a} / g\right), \text { and } D / B=\lambda_{a} /\left(g-\lambda_{a}\right),
\end{gathered}
$$

where $S=S_{m}(0) / q$ is the rate of volumetric sputtering of the target material without taking into account returning the sputtered particles due to back moving, $q$ is the density of the target material.

One can see the ration $\lambda_{a} / g$ determines the part of the sputtered target material, which is transferred to the collector, and $1-\lambda_{a} / g$ determines the part of the sputtered atoms returning to the target. Thus, in the average, even one collision of a sputtered atom with a gas molecule deprives the atom of a chance to reach the collector and it returns to the target. The fact that we neglected the first term in the right side of (3) indicates that we consider the role of diffusion of sputtered atoms in their transport to the collector surface to be insignificant. Indeed, at relatively low gas pressures, the mean free paths of sputtered atoms and their energy are quite large, and the process of sputtered material transfer to the collector occurs in the mode of almost forward flight movement of atoms with their rare collisions with gas molecules. With increasing pressure, the number of collisions increases and the energy of atoms decreases, approaching the energy of gas molecules, and the nature of the transfer of the sputtered atoms to the collector acquires a diffusion ("Brownian") character. Since the diffusion coefficient decreases with 
increasing pressure, there is an accumulation of slow sputtered atoms after thermalization near the target, and, accordingly, the diffusion flux of sputtered atoms will be mainly directed to the surface of the target. Thus, neglecting the diffusion flux in (3) has a physical basis, since this flux is directed, as we believe, mainly back to the target. This is reflected in formula (4).

\section{VALIDATION OF CALCULATION RESULTS WITH EXPERIMENT DATA AND DISCUSSION}

For validation of calculation results we will numerically determine the volumetric rates of deposition of the condensate on the collector, $D_{\text {call }}$, for the conditions in the experimental sputtering system with AGD and then compare $D_{\text {call }}$ with experimentally measured $D_{\exp }$ in the same experimental sputtering system with tantalum target and argon as working gas.

Let us estimate the value of $\lambda_{a}$ for the sputtering of tantalum by argon ions. Using the atomic radii of tantalum $R_{\mathrm{Ta}}=1.43 \AA$ and of $\operatorname{argon} R_{\mathrm{Ar}}=1.92 \AA$ [9], we obtain

$\lambda_{a}=(m+M) /\left[\pi\left(R_{\mathrm{Ta}}+R_{\mathrm{Ar}}\right)^{2} n M\right] \approx 2.17 \cdot 10^{-2} T / p$,

where $T$ is the gas temperature, the gas pressure $p$ is in [Pa].

Experimental reference conditions for tantalum film deposition are $U=5 \mathrm{kV}, j=0.46 \mathrm{~mA} / \mathrm{cm}^{2}, g=5 \mathrm{~cm}, p=$ 6.6 Pa, $T=573 \mathrm{~K}$. For this case, $\lambda_{a}=1.87 \mathrm{~cm}$. The experimental data of the authors on the deposition rate of tantalum films in argon are well approximated by the following formula, which is valid for said above operating mode of AGD [6]:

$$
D_{\text {exp }}=3.81(\sqrt{j U}-0.34) / g q,
$$

where $D_{\text {exp }}$ is in $[\mathrm{cm} / \mathrm{s}], g$ is in $[\mathrm{cm}], q$ is in $\left[\mu \mathrm{g} / \mathrm{cm}^{3}\right], U$ is in $[\mathrm{kV}], j$ in $\left[\mathrm{mA} / \mathrm{cm}^{2}\right]$. If we take the film density $q$ equal to the density of the target material (Ta), then for the above conditions, the volumetric deposition rate is $D_{\text {exp }}=5.4 \AA / \mathrm{s}[6]$.

For determining $D_{\text {call }}$ we use the theory of AGD, presented in [10] and based on the physical kinetics equations for distribution functions of ions $\mathrm{Ar}^{+}$and fast neutral atoms $\mathrm{Ar}^{0}$ after charge exchanges and the Poison equation for electric field in the dark cathode space, i.e. in the PSC layer. Approximations of the well known literature data on the cross section for argon ion resonance charge exchange and the secondary electron emission coefficients of the tantalum cathode at bombardment by $\mathrm{Ar}^{+}$ions and fast neutrals $\mathrm{Ar}^{0}$ were used for the dependencies of the cross section of charge exchange and the secondary electron emission coefficients on the velocity of primary particles. The numerical calculation was performed with the "big particles" method using the algorithm [10].

The approximations of the dependencies of the sputtering coefficients $k(v)$ for tantalum on the velocity $v$ of ions and fast atoms after charge exchanges are presented by (5), where velocity $v$ is in $[\mathrm{cm} / \mathrm{s}]$. The error of the approximations is a few percents [3].

The calculation results are presented in Table, where $j_{d}$ is total discharge current density, $j_{i . a}$ is ion current density from NG (from "plasma anode"), $e$ is the electron charge, $\Gamma_{c}$ is fast neutrals flow density at the cathode, $\Phi_{i}$ is flow density of Ta atoms sputtered by ions $\mathrm{Ar}^{+}, \Phi_{n}$ is flow density of Ta atoms sputtered by fast neutrals $\operatorname{Ar}^{0}, \Phi=\Phi_{i}+\Phi_{n}, S_{m}=m \Phi$.

$$
k(v)=\left\{\begin{array}{cc}
0 & v<1.39 \cdot 10^{6}-\mathrm{cm} / \mathrm{s}, \\
3 \cdot 10^{-4}\left(7.19 \cdot 10^{-7} v\right)^{18.72} & 1.39 \cdot 10^{6} \leq v \leq 1.7 \cdot 10^{6}-\mathrm{cm} / \mathrm{s}, \\
7.44 \cdot 10^{-55} v^{8,385} & 1.7 \cdot 10^{6} \leq v \leq 2.08 \cdot 10^{6}-\mathrm{cm} / \mathrm{s} \\
2.02 \cdot 10^{-28} v^{4,202} & 2.08 \cdot 10^{6} \leq v \leq 2.69 \cdot 10^{6}-\mathrm{cm} / \mathrm{s} \\
9.27 \cdot 10^{-13} v^{1,766} & 2.69 \cdot 10^{6} \leq v \leq 4.4 \cdot 10^{6}-\mathrm{cm} / \mathrm{s} \\
5.79 \cdot 10^{-6} v^{0,7431} & 4.4 \cdot 10^{6} \leq v \leq 4.9 \cdot 10^{7}-\mathrm{cm} / \mathrm{s}
\end{array}\right.
$$

The sputtering system parameters for Ta cathode at Ar pressure of $6.65 \mathrm{~Pa}$

\begin{tabular}{|l|c|c|c|c|c|c|}
\hline$U, \mathrm{kV}$ & \multicolumn{3}{|c|}{2.5} & \multicolumn{3}{c|}{5.0} \\
\hline$d, \mathrm{~cm}$ & 1.0 & 2.0 & 3.0 & 1.0 & 2.0 & 3.0 \\
\hline$j_{d}, \mathrm{~mA} / \mathrm{cm}^{2}$ & 0.753 & 0.142 & 0.052 & 2.436 & 0.462 & 0.169 \\
\hline$j_{i . a}, \mathrm{~mA} / \mathrm{cm}^{2}$ & 0.648 & 0.122 & 0.050 & 1.908 & 0.362 & 0.133 \\
\hline$e \Gamma_{c}, \mathrm{~mA} / \mathrm{cm}^{2}$ & 3.596 & 1.487 & 0.864 & 9.316 & 3.907 & 2.287 \\
\hline$e \Gamma_{c} / j_{i . a}, \mathrm{rel} \cdot \mathrm{units}$ & 5.549 & 12.19 & 17.28 & 4.882 & 10.79 & 17.20 \\
\hline$\Phi_{i}, 10^{15} \mathrm{~s}^{-1} \cdot \mathrm{cm}^{-2}$ & 2.066 & 0.259 & 0.068 & 8.754 & 1.212 & 0.350 \\
\hline$\Phi_{n}, 10^{15} \mathrm{~s}^{-1} \cdot \mathrm{cm}^{-2}$ & 6.090 & 1.534 & 0.593 & 25.06 & 7.371 & 3.249 \\
\hline$\Phi, 10^{15} \mathrm{~s}^{-1} \cdot \mathrm{cm}^{-2}$ & 8.156 & 1.793 & 0.661 & 33.81 & 8.583 & 3.599 \\
\hline$S, \AA / \mathrm{s}$ & 14.68 & 3.23 & 1.19 & 60.86 & 15.45 & 6.49 \\
\hline
\end{tabular}

One can see $e \Gamma_{c} / j_{i . a} \gg 1$ and $\Phi_{n}>\Phi_{i}$, that is the contribution of fast neutrals $\mathrm{Ar}^{0}$ in sputtering of the cathode material is larger than the contribution of ions due to the often charge exchange collisions of ions during movement to the cathode. At $U=5 \mathrm{kV}$, $d=2 \mathrm{~cm}$, the volumetric sputtering rate without 
returning sputtered atom to the target $S=15.45 \AA / \mathrm{s}$, that is much bigger than the experimental $D_{\text {exp }}$. However, taking into account (4), one can see $D_{\text {call }}=$ $15.45 \cdot(1.87 / 5)=5.78 \AA / \mathrm{s}$, that is close to the experimental value of $D_{\text {exp }}=5.4 \AA / \mathrm{s}$.

One can see $(1 \ldots 1.87 / 5)=0.625$ part or $62.5 \%$ of the primary sputtered atoms returns to the target. Herein, the ratio $D / B=1.87 /(5 \ldots 1.87)=0.6$ and $B / D=1.67$. All this shows that in the typical regime of AGD a large part of the initially sputtered material returns to the target-cathode.

\section{CONCLUSIONS}

Within the framework of the kinetic approach, the formulas for calculation of the transfer of the sputtered metal cathode (target) material in the anomalous glow discharge to the collector (substrate) in the planeparallel electrode system are derived. The formulas determine the ratio of the numbers of sputtered atoms that have reached the collector and returned back to the cathode as a result of collisions of sputtered atoms with working gas molecules. The formulas have been tested by the example of tantalum sputtering in an argon atmosphere and can be recommended for calculating the parameters of the coating deposition and ion cleaning of the target under conditions of an anomalous glow discharge.

It is shown that, under typical conditions for maintaining an anomalous glow discharge (AGD), most of the sputtered atoms return to the cathode.

This reduces either the rate of coating deposition on substrates or the rate and quality of ionic cleaning of the target. Reducing the backflow of the sputtered material can be achieved by reducing the gas pressure $p$ and the distance $g$ between the cathode (target) and the collector. However, in the order to obtain a significant result, it is necessary to reduce $p g$ to values at which conventional AGD is not maintained. In this case, it is necessary to apply additional methods for enhancing the gas ionization at low $p g$, for example, due to the magnetron effect (that is the use of crossed electric and magnetic fields).

\section{REFERENCES}

1. B.S. Danilin, V.Yu. Kireev. Usage of low-temperature plasma for etching and cleaning of materials. M.: «Energoatomizdat», 1989, p. 328.

2. B.S. Danilin. Usage of low-temperature plasma to deposition of thin films. M.: «Energoatomizdat», 1989.

3. Sputtering by Particle Bombardment. V.1. Physical Sputtering of Single-Element Solids / Ed. R. Behrisch. "Springer-Verlag», 1981.

4. A.von Engel. Ionized Gases. "AIP-Press", 1994, p. XIV.

5. F.M. Penning, J.H.A. Moubis. Cathode sputtering in a magnetic field // Proc. Kon. Ned. Akad. Wet. 1940, v. 43, № 1-5, p. 41-56.

6. Yu.G. Kononenko, A.I. Kuzmichev. Velocity of film deposition in diode discharge device // Vacuum technique and technology. 1992, v. 2, № 1, p. 13-18.

7. L.D. Landau, E.M. Lifshitz. Mechanics / 3rd ed. "Butterworth-Heinemann", 1976.

8. Yu.V. Gott. Interaction of particles with the matter in plasma investigations. M.: "Atomizdat", 1978.

9. Physical-chemical properties of elements: Handbook / Ed. G.V. Samsonov. Kiev: «Naukova Dumka», 1965.

10. O.D. Volpian, A.I. Kuzmichev, Yu.A. Obod, A.S. Sigov. Modelling of fast neutral atoms flow generation in channel rays of glow discharge // J. Phys. Conf. Ser. 2018, v. 1121, p. 012034 (1-4).

Article received 08.09.2020

\section{ПЕРЕРАСПРЕДЕЛЕНИЕ РАСПЫЛЕННОГО МАТЕРИАЛА В ПЛОСКОЙ ИОННО-ПЛАЗМЕННОЙ СИСТЕМЕ С АНОМАЛЬНЫМ ТЛЕЮЩИМ РАЗРЯДОМ}

\section{А.И. Кузьмичев, М.С. Мельниченко, В.Г. Шинкаренко, В.М. Шулаев}

Анализируется в кинетическом приближении перераспределение потока распыленного материала мишени (катода) между коллектором и мишенью в плоскопараллельной электродной системе с аномальным тлеющим разрядом. Распыление является результатом бомбардировки катода-мишени газовыми ионами, ускоренными в прикатодном слое пространственного заряда, и быстрыми нейтральными атомами, образующимися в результате резонансной перезарядки ионов. Распыленные атомы частично возвращаются на мишень из-за столкновений с газовыми молекулами. Получены формулы, подтвержденные в эксперименте, что позволяет корректно оценить соотношение потоков распыленного материала, осаждающихся на коллекторе и мишени. Результаты работы используются для расчета параметров процессов нанесения покрытий и ионной очистки мишени в условиях аномального тлеющего разряда.

\section{ПЕРЕРОЗПОДІЛ РОЗПИЛЕНОГО МАТЕРІАЛУ В ПЛОСКІЇ ІОННО-ПЛАЗМОВІЙ СИСТЕМІ 3 АНОМАЛЬНИМ ТЛІЮЧИМ РОЗРЯДОМ}

\section{А.І. Кузьмічев, М.С. Мельніченко, В.Г. Шінкаренко, В.М. Шулаєв}

Аналізується в кінетичному наближенні перерозподіл потоку розпиленого матеріалу мішені (катода) між колектором і мішенню в плоскопаралельній електродній системі 3 аномальним тліючим розрядом. Розпилення є результатом бомбардування мішені газовими іонами, прискореними в катодному шарі просторового заряду, і швидкими нейтральними атомами, що утворюються в результаті резонансного перезарядження іонів. Розпилені атоми частково повертаються на мішень через зіткнення 3 газовими молекулами. Отримано формули, підтверджені в експерименті, які дозволяють коректно оцінити співвідношення потоків розпиленого матеріалу, що осідають на колекторі і мішені. Результати роботи використовуються для розрахунку параметрів процесів нанесення покриттів і іонної очистки мішені в умовах аномального тліючого розряду. 